\title{
From Sources to Narratives: The role of Computer Graphics in Communicating Cultural Heritage Information
}

\author{
Simone Zambruno \\ University of Bologna, Ravenna, Italy \\ Alberto Urcia \\ Yale University, New Haven, USA \\ Manuela De Vivo, Antonino Vazzana, Alessandro Iannucci \\ University of Bologna, Ravenna, Italy
}

\begin{abstract}
During the last years, the topic of accessibility of cultural heritage is getting so important all around the Europe. For disseminating a research data and information, it is important to use a simple language and an effective communication. The data research produced by specialists has three formal levels: The third one of communication system aims to break barriers to reach a wide audience. The present study wants to demonstrate the role of images in the process of deductive inference by three dimensional (3D) reconstruction of cultural heritage. The case study of Federico da Montefeltro office shows how inter-disciplinary works and technological resource can help society to understand history and meaning of heritage.
\end{abstract}

Keywords: computer graphics, three dimensional (3D) modelling, virtual reconstruction, virtual tour, inter-disciplinary research

\section{Introduction}

Before investigating the role of computer graphics in the study of cultural heritage, it is worthwhile and necessary to answer the apparently obsolete but actually quite relevant question-Why it is so important and necessary to know how to communicate information relating to cultural heritage? Only then can we address the best way to achieve this communication.

\section{Accessibility of Cultural Heritage}

Information is a selection of the relevant characters of an object, enough to describe it at best. To spread information to a wide audience, it is important to use the right expressive form and the right tools to create an effective communication (Shannon, 1948). One of the primary roles of scientists, especially those in the field of humanities, is to increase the popular experience and understanding of culture, so the communication of the results of research is an integral part of the academic process of investigating cultural heritage. This is further

Simone Zambruno, Ph.D. candidate, Research Fellow, Department of Cultural Heritage, University of Bologna. Alberto Urcia, Associate Research Scientist, Department of Near Eastern Languages and Civilizations, Yale University. Manuela De Vivo, Master, Department of Cultural Heritage, University of Bologna.

Antonino Vazzana, Ph.D. candidate, Department of Cultural Heritage, University of Bologna.

Alessandro Iannucci, Associate Professor, Department of Cultural Heritage, University of Bologna. 
underlined as a statutory ordinance by the so-called "third mission" of the Italian universities. This mission currently belongs to Italian universities only, even though the goals aimed to develop new way to spread culture into the societies are primary topics within the programs of the European Union (EU). This is clearly demonstrated by the numerous projects that are included in the Horizon 2020 European grant. In fact, a further step in the interpretation of research data relating to objects of historical and archaeological value is needed to orient the results towards what is defined by Umberto Eco (1988) as the maximization of the cognitive enjoyment, that is, their accessibility by the widest possible audience. This interpretation must be independent of individual cognitive background and it must use a straightforward and simple language (Watzlawick, Beavin, \& Jackson, 1967; Gabellone, 2012). At this point, we can catch a glimpse of the role of computer sciences and new types of media.

\section{Communication of Research Data}

The data produced by a research project navigates through three formal levels. The first level is that of the raw data. Irrespective of the source (e.g., archaeology, archives, artifacts, or monuments), raw data can only be meaningful to someone that is technically able to process it in order to produce new types of information. Even within the context of the average excavation project, the raw data is accessed by only a very restricted number of specialists.

The second level derives from the first and takes the form of the publication of the raw data within the confines of the scientific community through the medium of technical journals. Even though the range of user who can access the data is enhanced, the second level, like the first, does not make the information available in a way that engages wider popular interest or interpretative skills.

\section{Images for Accessibility}

The third level of the communication system aims to break this barrier in order to reach a larger audience. No single solution will fulfill this need, but the utilization of computer graphics has proven very effective, especially whereas the material or physical part of cultural heritage is involved. This is primarily image-based because images are a type of data that can release the information encoded within them with less abstraction than is the case for other media (e.g., text). Therefore, images are easier and more straightforward to understand due the process of deductive inference by the viewer (Zaccarini et al., 2013; Kortbek \& Grønbæk, 2008). If images and three dimensional (3D) models are used consciously, people who produce the may narrow down the risk of affecting the informative content with subjectivity that might result in trivialization and the loss of information. Similarly, the image user is discouraged from formulating thoughts that are too far from the original message of the photo, and so not relevant (Peirce, 1932). Computer graphics can therefore work simultaneously as medium and as message, perfectly fitting McLuhan's (1964) axiom "the medium is the message."

McLuhan's (1964) thoughts can frame computer graphics-based technology as a medium (or means) that because of its technical nature, it is able stimulate contemporary more than a single sense (cold) inducing the users to elaborate a more complex and synergic interaction with the artifact versus other type of media (as recorded voice or text) that are defined as "warm." So, cold media they are possibly working better to help or guide the process of interpretation of the messages that created the reconstructive model is intending to tell.

The widespread and effective use of computer graphics to communicate information relating to cultural heritage is quite visible. It is no longer restricted to the realm of the theory of communication or semiotics but 
is rather part of the technologic phenomenon of "digital convergence" (Muller, 1999; Marty, 2014). According to this phenomenon, which has existed for several decades, traditional methods of learning and communication are converging and matching onto digital counterparts. This phenomenon has a multitude of causes, the discussion of which lies beyond the scope of this paper. Instead, it is sufficient to highlight that this process, with increasing speed and extreme results having mutated the habits and expectations of users. The impact of these technologies on everyday life is now such that their use is now virtually mandatory in order to reach a wide audience.

\section{Inter-Disciplinary Research}

With this in mind, it is easy to understand the importance of a 3D reconstruction. Such reconstructions, for example, can be loaded into mobile devices and accessed using specific apps through which the users can navigate and enjoy them. The 3D models can also be inserted in web pages to make them interacting with a wider dataset of related information including publications on journals. This form of communication relating to cultural heritage is easily engaged with by the non-specialist, but it is also a very effective means by which to study and disseminate information within a research environment.

The application of computer graphics in the study of monuments, for instance, not only fulfills the curiosity of non-specialized users, but is also a very helpful tool through which artifacts and their contexts may be scientifically investigated (Olivito et al., 2016). The inter-disciplinary nature of this research has brought computer graphics specialists together with historians and archaeologists. In the first phases of the workflow, the production of 3D models of structures assists in the interpretation of raw data, allowing measurement of building elements and spaces, analytical observation, and formulation of ideas that will support functional and reconstructive hypotheses (De Paolis \& Mondelli, 2016).

\section{D Modeling of Federico da Montefeltro Studiolo}

The Federico da Montefeltro office (studiolo) into the Palazzo Ducal of Urbino is a good case study, developed to achieve two specific goals. The first one is part of a wider project aimed to study and record the painted music on Renaissance buildings in Italy, involved an accurate 3D modeling of the room on which virtually restore the original integrity of the upper level decorations (see http://www.framelab.unibo.it/palaces/). These decorated areas, especially the portraits of distinguished men selected for display and observation by Federico while practicing meditation, were partially lost or moved away the centuries. Following on from the first, the second goal is the verification of the disposition of these portraits according to the hypotheses formulated by various art historians (Rotondi, 1995).

The 3D modeling of studiolo was made in 2015 with open source software Blender, by FrameLAB in cultural heritage, Department of University of Bologna. The creation of a metrically accurate and reliable digital replica of the studiolo and its decoration allowed the comparison of the model with documentation relating to the possible location of the missing parts of the decoration and the validation of Cheles (1986) theory (see Figure 1, the missing paints have been relocated virtually using Blender software following the information coming from the specific literature). The 3D model of the room, realistically textured using photographs, also provided a virtual reconstruction that could be used effectively to communicate cultural heritage information more widely (see Figure 2). We therefore created a virtual tour allowing the user to interactively navigate the room thanks to a series of inserted multimedia contents: images, videos, text, and 
sounds. Sound was particularly significant, considering that music is the major topic represented in the paintings. Among the wooden inlays in Federico's room in Urbino, which depict numerous musical instruments, it is also possible to find the notes of two anonymous polyphonic tracks that are known only thanks to this decoration. The first one is called "Bella Gerit" located on the left side of the entrance wall. The second is called "J'aypris amour" located on the opposite wall. Combining the sound of this music into the virtual tour that we created, it is not only possible to characterize and satisfy the sense of the vision, but also to enrich the experience with original sounds that might offer a close reproduction of what Federico was possibly feeling during his stay. The attachment of all the multimedia content to the model maximized the cognitive experience (see Figure 3), according to McLuhan's theory.

The case of Federico's room clearly demonstrates the potential of computer graphics when applied to the study and development of cultural heritage.

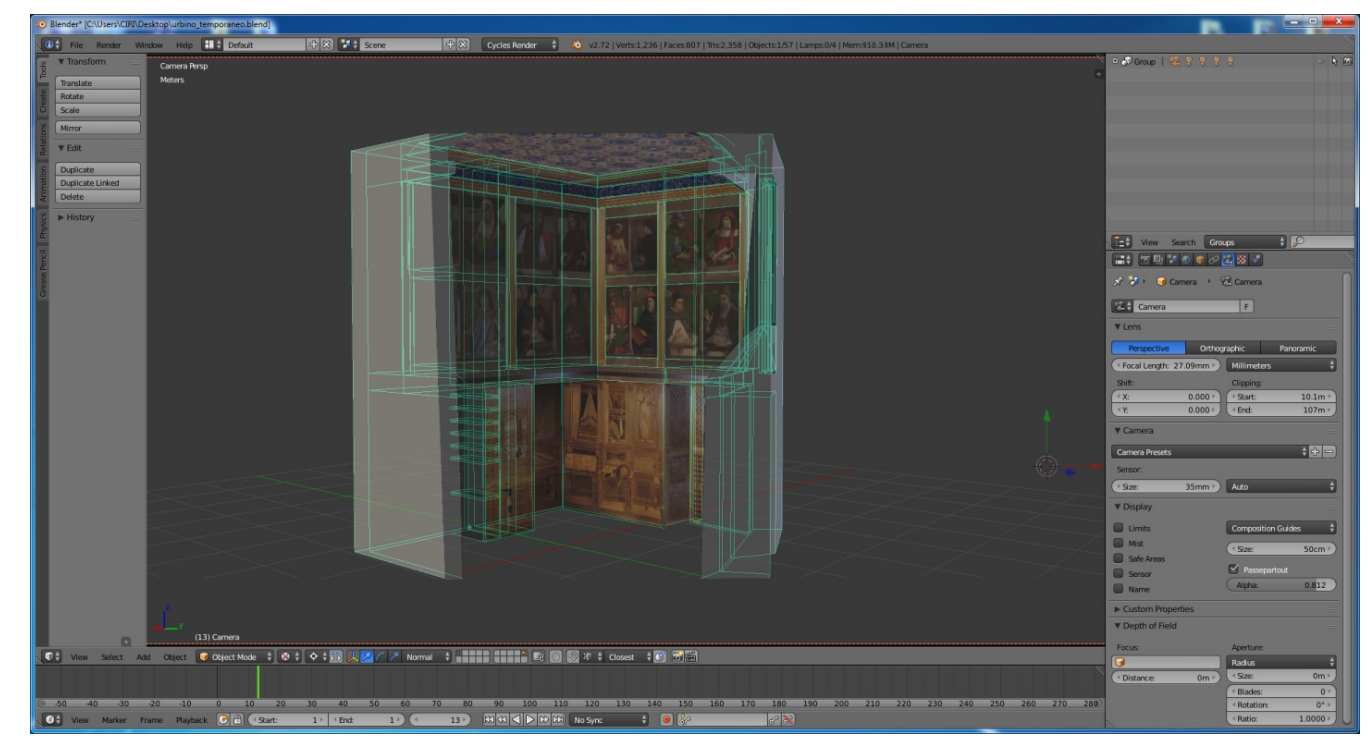

Figure 1. 3D modeling of the decorated room in Urbino (Italy).

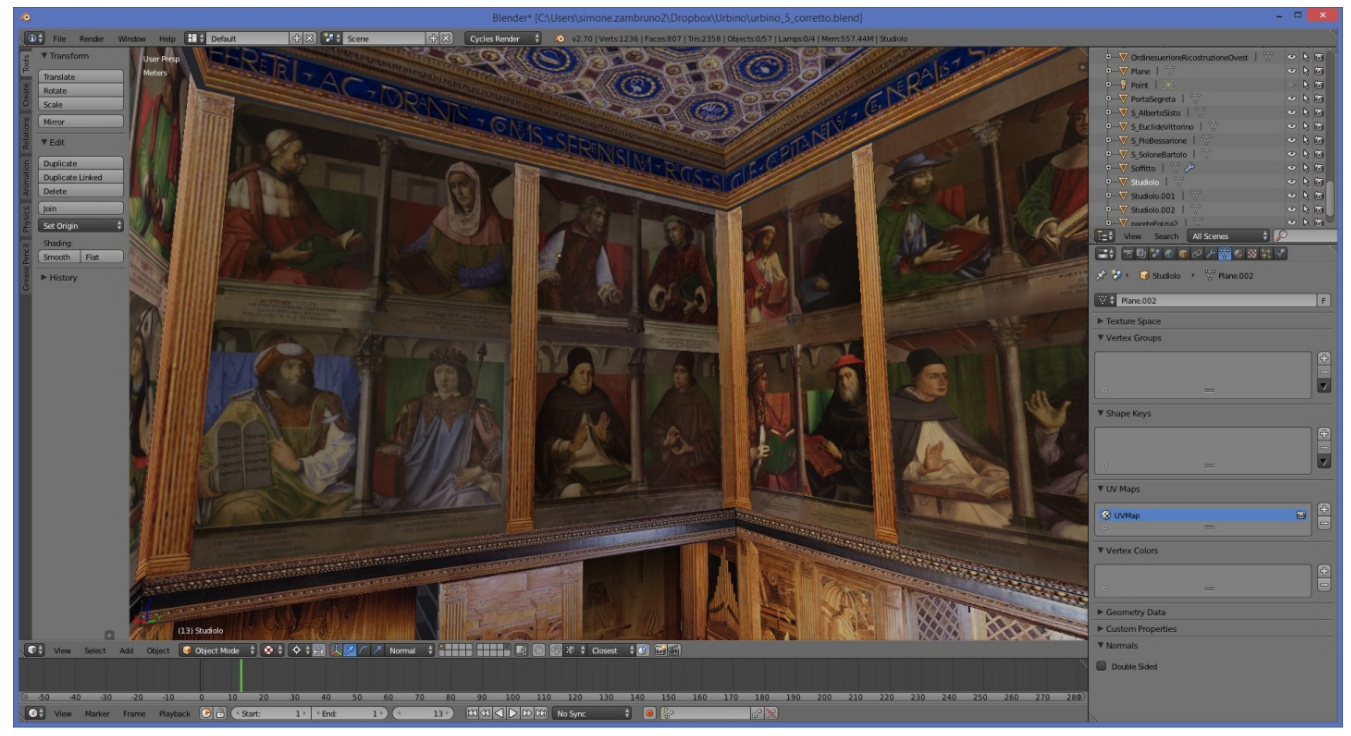

Figure 2. Characterization of the 3D model using photographic textures. 


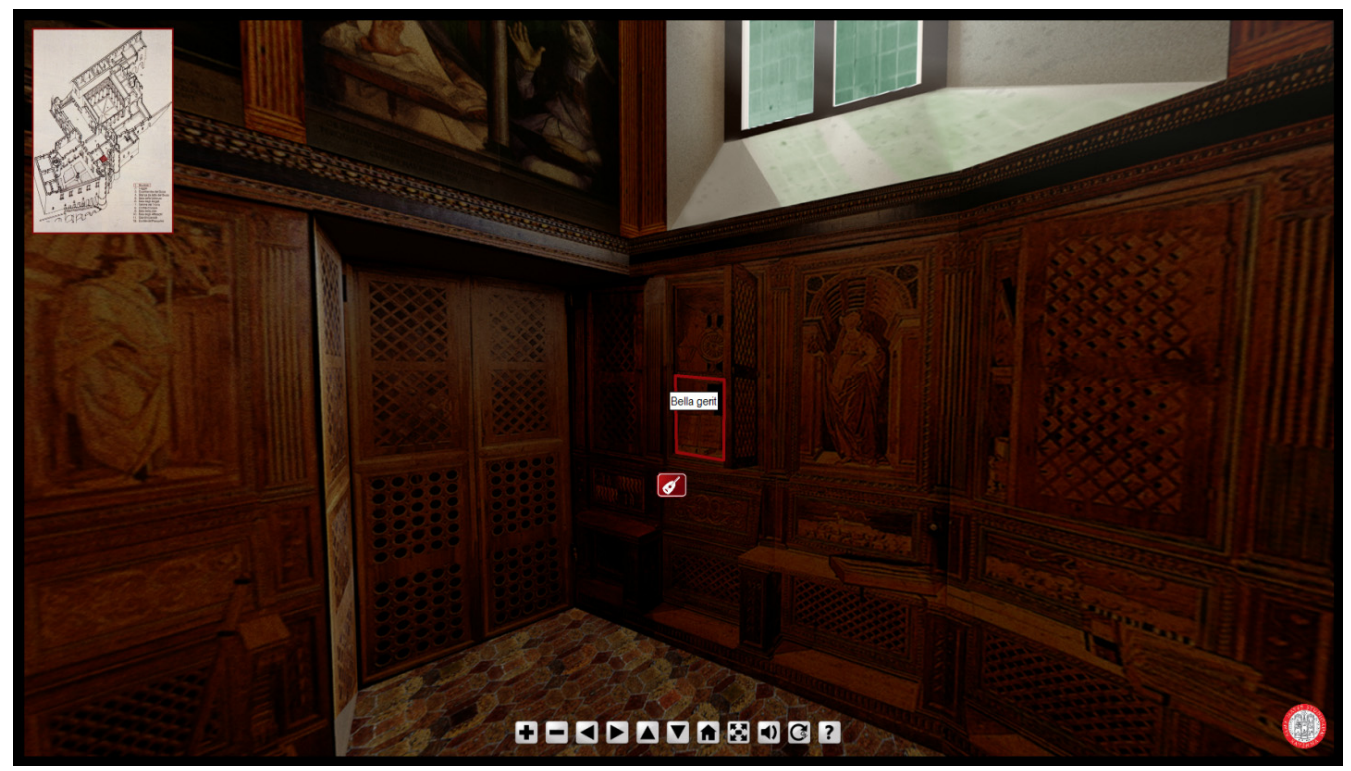

Figure 3. Screenshot of the virtual tour of the studiolo created to let users interacting to the visual and audio contents that have been embedded using computer graphics applications.

\section{Conclusion}

Computer graphics are one of the most important resources for scholars and experts for the purposes of research and education. The increasing affordability of computer hardware and availability of free open-source versions of most kinds of third-party software on the Internet mean that virtual reconstructions are now a viable and economic form of reproduction.

The application of computer graphics to cultural heritage is also attractive to potential funders (Tallon \& Walker, 2008). Projects that focus in creating multimedia stations, interactive exhibitions or virtual museum are not only appreciated, but are often a fundamental prerequisite to approval. For example, a major concern expressed by the committee of the European Framework Programme Horizon 2020 ${ }^{1}$, is the tangible benefit that technological innovation embedded in each project will have for the European population. It would be difficult to find a better tool than Computer Graphics for combining information and communications technology (ICT) and the humanities to fulfill the Horizon 2020 goals.

\section{References}

Agenzia Nazionale di Valutazione del Sistema Universitario e della Ricerca (ANVUR). (2016). Valutazione terza missione. Retrieved from http://www.anvur.org/index.php?option=com_content\&view=article\&id=875\&Itemid=628\&lang=it\#

Cheles, L. (1986). The studiolo of Urbino: An iconographic investigation. Pennsylvania: Pennsylvania State University Press. Ciotti, F., \& Roncaglia, G. (2010). II mondo digitale. Roma-Bari: Laterza.

De Paolis, L. T., \& Mondelli, A. (2016). Augmented reality, virtual reality, and computer graphicsin. Third International Conference, AVR 2016, Lecce, Italy.

Eco, U. (1988). Le isole del tesoro: proposte per la riscoperta e la gestione delle risorse culturali (Treasure islands: Proposals for the rediscovery and menagement of cultural resouces). Electa, Milano, Italy.

European Commission. (2014). HORIZON 2020 in brief: The EU Framework Programme for research \& innovation. Retrieved from:

\footnotetext{
${ }^{1}$ About the Horizon 2020 projects that have already been funded with the aim to test and employ computer graphics to solve problems and produce new results see the following link: http://cordis.europa.eu/search/result it?q=contenttype $=\% 27$ project\%27\%20AND\%20/project/relations/associations/relatedCall/call/identifier=\%27H2020-REFLECTIVE-7-2014\%27.
} 
FrameLab. (2013). La musica dipinta (The painted music). Retrieved from http://www.framelab.unibo.it/palaces/

Gabellone, F. (2012). La trasparenza scientifica in archeologia virtuale: Una lettura critica al principio n.7 della Carta di Siviglia (Scientific trasparency in virtual archaeology. A critical reading of principle 7 of Sevilla Charter). In D. Arnold \& G. Geser (Eds.), Scires-IT Scientific Research and Information Technology (pp. 99-124). Caspur-Ciber Publishing. Retrieved from http://epoch-net.org/site/publications/activity-report/

Guidobaldi, N. (1995). La musica di Federico: Immagini e suoni alla corte di Urbino. Retrieved from https://ec.europa.eu/programmes/horizon2020/en/news/horizon-2020-brief-eu-framework-programme-research-innovation

Kortbek, K. J., \& Grønbæk, K. (2008). Communicating art through interactive technology: New approaches for interaction design in art museums. In K. Tollmar \& B.Jönsson (Eds.), Proceedings of The 5th Nordic Conference on Human-Computer Interaction: Building Bridges (pp. 229-238). New York, N.Y.: ACM Press.

Marty, P. F. (2014). Digital convergence and the information profession in cultural heritage organizations: Reconciling internal and external demands. Library Trends, 62(3), 613-627.

McLuhan, M. (1964). Understanding media: The extension of man. New York, N.Y.: McGraw-Hill.

Mueller, M. (1999). Digital convergence and its consequences: The economics and politics of the new media. Javnost the Public, $6(3), 11-28$.

Olivito, R., Taccola, E., \& Albertini, N. (2016). Theory, methods, and tools for the study and dissemination of knowledge in the archaeological practice. In S. Campana \& M. Forte (Eds.), Digital methods and remote sensing in Archaeology (pp. 475-497). USA: Springer Publishing.

Peirce, C. S. (1932). The collected papers of Charles Sanders Peirce, Vol. II: Elements of logic. Cambridge: Harvard University Press.

Rotondi, P. (1950). II Palazzo ducale di Urbino. Urbino: Istituto d'arte per il libro.

Shannon, C. (1948). A mathematical theory of communication. Bell System Technical Journal, 27(3), 379-423.

Tallon, L., \& Walker, K. (2008). Digital technologies and the museum experience: Handheld guides and other media. New York, N.Y.: Altamira Press.

Watzlawick, P., Beavin, J. H., \& Jackson, D. D. (1967). Pragmatics of human communication: A study of interactional patterns, pathologies, and paradoxes. New York, N.Y.: W. W. Norton \& Company.

Zaccarini, M., Iannucci, A., Orlandi, M., Vandini, M., \& Zambruno, S. (2013). A multi-disciplinary approach to the preservation of cultural heritage: A case study on the Piazzetta degli Ariani, Ravenna. In Proceedings of The 2013 Digital Heritage International Congress (pp. 337-340), IEEE The Institute of Electrical and Electronics Engineers, Inc. 